\title{
Basal Levels and GnRH-induced Responses of Peripheral Testosterone and Estrogen in Holstein Bulls with Poor Semen Quality
}

\author{
Bhuminand DEVKOTA ${ }^{1,2)}$, Ken-Ichi TAKAHASHI ${ }^{3)}$, Shigenori MATSUZAKI ${ }^{3)}$, \\ Motozumi MATSUI ${ }^{1)}$, Akio MIYAMOTO ${ }^{4)}$, Norio YAMAGISHI ${ }^{2)}$, Takeshi OSAWA ${ }^{2)}$, \\ Tsutomu HASHIZUME'), Yoshiaki IZAIKE ${ }^{2)}$ and Yoh-Ichi MIYAKE')
}

\begin{abstract}
${ }^{1)}$ Department of Veterinary Medicine, Obihiro University, Obihiro 080-8555, ${ }^{2)}$ Faculty of Agriculture, Iwate University, Iwate 020-8550, ${ }^{3)}$ Genetics Hokkaido, Shimizu 089-0103 and ${ }^{4)}$ Graduate School of Animal and Food Hygiene, Obihiro University, Obihiro 080-8555, Japan
\end{abstract}

\begin{abstract}
The present study investigated the basal levels and GnRH-induced responses of peripheral testosterone and estrogen in Holstein bulls with poor semen quality. On the basis of semen parameters, bulls (n=5) having poor semen quality were selected as experimental bulls, and good semen quality bulls $(n=4)$ were used as control bulls. Both groups were treated intramuscularly once with $\mathrm{GnRH}(250 \mu \mathrm{g}$ of fertirelin acetate). Blood samples were collected at $-1 \mathrm{day}(\mathrm{d})$, $-30 \mathrm{~min}$ and $0 \mathrm{~h}$ (treatment) followed by every $30 \mathrm{~min}$ for $5 \mathrm{~h}$ and 1, 3 and $5 \mathrm{~d}$ post-GnRH treatment (PGT), and LH, testosterone and estradiol- $17 \beta\left(\mathrm{E}_{2}\right)$ concentrations were measured. The pretreatment concentrations were used as basal levels. The percentage increments based on the 0 -h levels were calculated per bull for each sampling time until $5 \mathrm{~h}$ PGT, and differences were compared between the experimental and control groups. The PGT concentrations of testosterone and basal and PGT concentrations of $\mathrm{E}_{2}$ were significantly lower in the experimental group. The testosterone increment in the experimental group was delayed and significantly lower from 1 to $5 \mathrm{~h}$ PGT than those in the control group. It can be suggested that bulls with poor semen quality have delayed and lower GnRH-induced testosterone response and may also have lower estrogen levels.

Key words: Bull, Estrogen, GnRH-induced response, Poor semen quality, Testosterone
\end{abstract}

(J. Reprod. Dev. 57: 373-378, 2011)

B ull fertility is very important because one bull may serve around twenty females under natural service conditions or hundreds of thousands under an artificial insemination program. Some bulls produce less or substandard quality spermatozoa, which results in a smaller number of inseminates and may also impair fertility postinsemination or postservice. The testes of such bulls are primarily characterized by mixed atrophied lesions, with abundant Sertoli cell-only tubules, in which the reversion of Sertoli cell maturity is possible [1]. However, it is difficult to understand their testicular physiology precisely and determine their future utilization.

Different types of spermatogenic arrests leading to impaired fertility and their relationships with gonadotropic and gonadal steroid hormones have been described in men [2-4], rats [5] and bulls [6, 7]. Although moderately predictable for the absolute fertility level, semen quality parameters of motility, sperm number and sperm morphology are valuable in identifying bulls of very low fertility [8]. The peripheral level of gonadotropins and testicular steroids may not be related to the testicular pathology in bulls, which points towards other abnormalities, including impaired gonadal responses to those hormones or secretion of intratesticular factors [7]. Some early studies have shown that the pituitary and testicular response

Received: September 17, 2010

Accepted: January 5, 2011

Published online in J-STAGE: February 14, 2011

(C)2011 by the Society for Reproduction and Development

Correspondence: B Devkota (e-mail: bhumi@iwate-u.ac.jp) with exogenous GnRH has no relation with semen production [9], sperm parameters [10] and libido [11] of bulls, while one study considered the testosterone response to $\mathrm{GnRH}$ to be a more reliable predictor of bull fertility than other reproductive measurements such as semen quality and scrotal circumference parameters [12]. On the other hand, recent studies have largely reported about the role of estrogen in physiological regulation of the male reproductive tract. The activity of estrogen on spermatogenesis appears to involve germ cell proliferation, differentiation and the final maturation of spermatids, as well as germ cell survival and apoptosis [13]. In the bovine, we have recently reported that estrogen may be important for the functioning of postpubertal bull testes, in which it may regulate spermatozoa motility in vivo [14]. It is, therefore, important to have a further understanding about the possible role of estrogen in the semen quality of mature bulls. The objectives of the present study were to evaluate the semen quality parameters of Holstein breeding bulls to identify them as bulls having poor semen quality or good semen quality and to compare between them the basal levels and GnRH-induced responses of peripheral testosterone and estradiol- $17 \beta\left(\mathrm{E}_{2}\right)$.

\section{Materials and methods}

\section{Animals and semen evaluation}

Semen donating Holstein bulls of Genetics Hokkaido $(n=8)$ and the Niikkappu station of the National Livestock Breeding Center $(n=1)$, Japan, were used in the present study. The experimental 
usage of animals and experimental design were approved by both centers and the Obihiro University Laboratory Animal Care and Use committee. These two breeding bull stations had the most similar management practices. At both stations, semen was collected once or twice every week by ejaculation two to three times per ejaculation day using an artificial vagina, the volume was measured and the semen was then evaluated for several semen parameters, such as spermatozoa concentration and progressive motilities after collection (MAC) and after freezing in liquid nitrogen and thawing (MAT), using routine techniques. Bulls $(n=5)$ having an MAC $<60 \%$ or an MAT $<30 \%$ continuously for two to four months were identified as bulls with poor semen quality (experimental bulls). Out of them, two bulls were young (1.5 and 2.5 yrs old) and other three bulls were older (5 to 7 yrs old). Other bulls $(n=4)$ having an average MAC $>60 \%$ or an average MAT $>30 \%$ were randomly selected among the good semen quality bulls and used as the control (control bulls). Among them, one bull was young (2.5 yrs old), and three bulls were older ( 5 to 7 yrs old). Since the semen quality of the young and older bulls differed, comparison of the semen parameters in the young (Table 1) and older bulls (Table 2) for both groups are presented separately. Moreover, different types of morphological abnormalities, after staining with Eosin-Nigrosin stain were also studied in some of the semen samples from four out of the five experimental bulls before freezing and after freezing and thawing (Table 3). These included abnormalities of the head, neck, midpiece and tail, head only spermatozoa and spermatozoa having a cytoplasmic droplet. One semen sample after freezing and thawing from one control bull was also studied for similar abnormalities as a reference and to show a tentatively acceptable abnormality percentage.

\section{Animal treatment and blood sampling}

After grouping bulls on the basis of semen parameters, all bulls in both the groups were subsequently treated intramuscularly once with GnRH (250 $\mu$ g of fertirelin acetate, Conceral ${ }^{\circledR}$, ScheringPlough Animal Health, Tokyo, Japan). Blood samples were collected at -1 day (d), -30 min and $0 \mathrm{~h}$ (time of treatment) followed by every $30 \mathrm{~min}$ for $5 \mathrm{~h}$ and $1 \mathrm{~d}, 3 \mathrm{~d}$ and $5 \mathrm{~d}$ post-GnRH treatment (PGT). Plasma was separated and harvested immediately at $-30 \mathrm{C}$ until assayed to measure the $\mathrm{LH}$, testosterone and $\mathrm{E}_{2}$ concentrations.

\section{Hormone assays}

The plasma LH concentrations were measured only for four animals, two animals from each group, and testosterone and $E_{2}$ were measured for all nine animals. LH was measured by a double-antibody radioimmunoassay as described elsewhere [15]. The LH standard preparation and hormone for iodination was USDA- b LH-B-6 (USDA Animal Hormone Program, Beltsville, MD, USA). An antiserum to bLH was generated in guinea pigs (Laboratory of Animal Reproduction, Iwate University, Japan), and goat anti-guinea pig IgG serum (secondary antibody) was supplied by Dr T Matozaki (Institute for Molecular and Cellular Regulation, Gunma University, Maebashi, Japan). The intra- and interassay CVs were 11 and $8 \%$, respectively. Testosterone and $E_{2}$ concentrations were measured by double antibody enzymeimmunoassay
(EIA) after diethyl ether extraction of steroids, which were reconstituted in neutral buffer. Samples were analyzed in duplicate as described previously [14]. The intra-assay and interassay CVs for the testosterone and $\mathrm{E}_{2}$ assays were 4.7 and $8.7 \%$ and 7.1 and $14.9 \%$, respectively.

\section{Definitions of basal concentrations, $5 \mathrm{~h}$ PGT response and $5 d$ \\ PGT concentrations}

Basal concentrations of the hormones were the average concentrations before the time of treatment $(1 \mathrm{~d},-30 \mathrm{~min}$ and $0 \mathrm{~h})$. The responses for $5 \mathrm{~h} \mathrm{PGT} \mathrm{(} 0.5$ to $5 \mathrm{~h}$ ) were calculated in terms of increment percentage with regard to the concentration at the time of treatment $(0 \mathrm{~h})$. Similarly, $5 \mathrm{~d}$ PGT concentrations were the average of $1 \mathrm{~d}$ to $5 \mathrm{~d}$ PGT ( $1 \mathrm{~d}, 3 \mathrm{~d}$ and $5 \mathrm{~d}$ ). The average concentrations for $5 \mathrm{~h}$ PGT were also calculated while comparing the concentrations between the experimental and control groups. Since the basal and GnRH stimulated hormone concentrations in young and older bulls were almost the same, the analyses of hormonal data from the group of experimental and control bulls were carried out together. Moreover, since LH was measured only for two experimental and two control bulls, the individual bull data are presented while showing the response for $5 \mathrm{~h}$ PGT.

\section{Statistical analysis}

All numerical data are expressed as means \pm SEM. Data for semen parameters were compared between the experimental and control groups by the Student's $t$-test. The increment percentage of testosterone and $\mathrm{E}_{2}$ until $5 \mathrm{~h}$ PGT was analyzed by repeated measures ANOVA, and Dunnett's multiple comparisons and the Student's $t$-test were applied to determine the significance in increments considering the $0 \mathrm{~h}$ level as a control and to determine the difference between the groups for the same period, respectively. Similarly, the nonparametric Wilcoxon / Kruskal-Wallis test was used to compare the basal, 0.5 to $5 \mathrm{~h}$ PGT and 1 to $5 \mathrm{~d}$ PGT concentrations between the experimental and control groups. JMP 5.0.1 software (SAS Institute Japan) was used for statistical analysis, and probability values of $\mathrm{P}<0.05$ were considered to be significant.

\section{Results}

\section{Semen parameters in experimental and control bulls}

Young experimental bulls had $<60 \%$ progressive motility after collection and $<30 \%$ progressive motility after freezing and thawing, whereas a young control bull had $>60 \%$ progressive motility after collection and $>30 \%$ progressive motility after freezing and thawing (Table 1). All of the four routinely evaluated semen parameters, semen volume, spermatozoa concentration, MAC and MAT, in the older experimental bulls were lower $(\mathrm{P}<0.01)$ compared with the older control bulls (Table 2). Moreover, in four experimental bulls studied for spermatozoa abnormalities before freezing and after freezing and thawing, the total average percentage of spermatozoa with morphological abnormalities in the head, neck, midpiece and tail and with head only spermatozoa and cytoplasmic droplets was $>30 \%$. When examined for similar kinds of abnormalities after freezing and thawing in a control bull as a reference, similar kinds of abnormalities were observed in only $12.4 \%$ 
Table 1. Comparison of the semen parameters between young bulls at 18-30 months of age with good (control bull) and poor semen quality (experimental bulls)

\begin{tabular}{lcc}
\hline Semen parameters* & Experimental bulls $(\mathrm{n}=2)$ & Control bulls $(\mathrm{n}=1)$ \\
\hline Semen volume $(\mathrm{ml})$ & $7.3 \pm 0.5$ & $6.2 \pm 0.4$ \\
Spermatozoa concentration $\left(\times 10^{6} / \mathrm{ml}\right)$ & $614.3 \pm 31.3$ & $793.5 \pm 62.3$ \\
Progressive motility after collection $(+++\%)$ & $44.5 \pm 2.4$ & $72.8 \pm 1.2$ \\
Progressive motility after freezing and thawing $(+++\%)$ & $9.4 \pm 1.3$ & $49.0 \pm 1.8$ \\
\hline
\end{tabular}

* The semen parameters were evaluated for 20 and 21 collection days in two experimental bulls and for 10 collection days in one control bull.

Table 2. Comparison of the semen parameters between the older bulls (5-7 years of age) having good (control bulls) and poor semen quality (experimental bulls)

\begin{tabular}{lcc}
\hline Semen parameters* & Experimental bulls $(\mathrm{n}=3)$ & Control bulls $(\mathrm{n}=3)$ \\
\hline Semen volume $(\mathrm{ml})$ & $11.8 \pm 0.3^{\mathrm{a}}$ & $16.2 \pm 0.4^{\mathrm{b}}$ \\
Spermatozoa concentration $\left(\times 10^{6} / \mathrm{ml}\right)$ & $486.4 \pm 26.7^{\mathrm{a}}$ & $947.2 \pm 46.4^{\mathrm{b}}$ \\
Progressive motility after collection $(+++\%)$ & $57.6 \pm 0.6^{\mathrm{a}}$ & $70.3 \pm 0.6^{\mathrm{b}}$ \\
Progressive motility after freezing and thawing $(+++\%)$ & $26.9 \pm 1.2^{\mathrm{a}}$ & $37.0 \pm 0.8^{\mathrm{b}}$ \\
\hline
\end{tabular}

Different superscripts between the groups denote for significant differences $(\mathrm{P}<0.01)$. ${ }^{*}$ The semen parameters were evaluated for $27.0 \pm 4.9$ and $30.0 \pm 8.3$ collection days in the experimental and control bulls, respectively.

Table 3. Average percentage of different types of morphological abnormalities in four poor semen quality (experimental) bulls and one good semen quality (control) bull

\begin{tabular}{lccc}
\hline Morphological abnormalities* & \multicolumn{2}{c}{ Experimental bulls ( $\mathrm{n}=4)$} & Control bull $(\mathrm{n}=1)$ \\
\cline { 2 - 3 } & Before freezing & After freezing and thawing & After freezing and thawing \\
\hline Head abnormality & $4.9 \pm 1.1$ & $4.9 \pm 1.3$ & 2.7 \\
Neck abnormality & $1.6 \pm 0.4$ & $0.7 \pm 0.3$ & 0.7 \\
Midpiece abnormality & $11.5 \pm 4.3$ & $8.8 \pm 3.0$ & 1.3 \\
Tail (including coiled tail) abnormality & $4.2 \pm 0.2$ & $10.4 \pm 2.5$ & 6.4 \\
Head only spermatozoa & $4.7 \pm 0.9$ & $3.3 \pm 0.7$ & 1.0 \\
Cytoplasmic droplet & $6.6 \pm 3.2$ & $7.7 \pm 3.2$ & 0.3 \\
Total & $33.4 \pm 0.6$ & $34.5 \pm 2.9$ & 12.4 \\
\hline
\end{tabular}

* The number of semen samples used to study the morphological abnormalities of the spermatozoa in the experimental bulls ranged from a single sample to 13 collection day samples from before freezing and from a single sample to 3 collection day samples from after freezing and thawing, and a single collection day sample from a control bull was used to study the same parameters as reference values.

of the total spermatozoa studied (Table 3), which was much less than that observed in the experimental bulls. In addition, there were considerably more midpiece abnormalities and cytoplasmic droplets in the spermatozoa of experimental bulls compared with the control bull.

\section{Comparison of the average basal, 0.5 to $5 \mathrm{~h}$ PGT and 1 to $5 \mathrm{~d}$} PGT concentrations of hormones between the experimental and control bulls

The comparison of the average basal, 0.5 to $5 \mathrm{~h}$ PGT and 1 to $5 \mathrm{~d}$ PGT concentrations of $\mathrm{LH}$, testosterone and $\mathrm{E}_{2}$ is shown in Table 4. In both experimental and control bulls, the concentrations of hormones during 1 to $5 \mathrm{~d}$ PGT were related to the respective basal concentrations, although high bull-to-bull variations were observed in both groups, and the variation was larger among the experimental bulls. All three types of LH concentrations and the basal testosterone concentration were similar in both the experimental and control groups, whereas a lower $(\mathrm{P}<0.05)$ basal $\mathrm{E}_{2}$ concentration was observed in experimental group. Lower $(\mathrm{P}<0.01)$ average concentrations during 0.5 to $5 \mathrm{~h}$ PGT were observed for both testosterone and $\mathrm{E}_{2}$. Moreover, lower average concentrations $(\mathrm{P}<0.05$ for testosterone and $\mathrm{P}<0.01$ for $\mathrm{E}_{2}$ ) were observed in the experimental bulls during 1 to $5 \mathrm{~d}$ PGT.

\section{Increments of $L H$, testosterone and $E_{2}$ during $5 \mathrm{~h}$ PGT}

The per bull percentage increment of $\mathrm{LH}$ is shown in Fig. 1. The LH increment in one experimental bull (E2) was interestingly very high, and in another experimental bull (E1), it was even lower than in the control bulls (C1 and C2). However, the time of the peak LH PGT was almost the same (between 2 to $3 \mathrm{~h}$ ) in all bulls. Interestingly, when the per bull increments of testosterone (Fig. 2) were analyzed, four out of the five (80\%) experimental bulls had peak testosterone increments of $<60 \%$. Among them, one bull had peak increments of only $20.4 \%$. On the other hand, all the control bulls 
Table 4. Average basal and 0.5 to $5 \mathrm{~h}$ post-GnRH treatment (PGT) and 1 to $5 \mathrm{~d}$ PGT concentrations of testosterone and estradiol-17 $\beta$ in the experimental and control groups

\begin{tabular}{lcccccc}
\hline \multirow{2}{*}{ Hormones* } & \multicolumn{3}{c}{ Average concentrations } \\
\cline { 2 - 7 } & \multicolumn{3}{c}{ Basal } & \multicolumn{2}{c}{0.5 to 5 h PGT } & \multicolumn{2}{c}{ 1 to 5 d PGT } \\
\cline { 2 - 7 } & Experimental & Control & Experimental & Control & Experimental & Control \\
\hline LH $(\mathrm{ng} / \mathrm{ml})$ & $0.3 \pm 0.0$ & $0.3 \pm 0.1$ & $6.8 \pm 2.1$ & $5.9 \pm 1.0$ & $0.8 \pm 0.5$ & $0.3 \pm 0.1$ \\
Testosterone $(\mathrm{ng} / \mathrm{ml})$ & $6.2 \pm 1.0$ & $7.7 \pm 0.6$ & $9.3 \pm 0.5^{\mathrm{a}}$ & $13.3 \pm 0.5^{\mathrm{b}}$ & $5.8 \pm 1.0^{\mathrm{a}}$ & $7.7 \pm 0.7^{\mathrm{c}}$ \\
Estradiol-17 $\beta(\mathrm{pg} / \mathrm{ml})$ & $3.8 \pm 1.0^{\mathrm{a}}$ & $5.8 \pm 0.5^{\mathrm{c}}$ & $4.7 \pm 0.4^{\mathrm{a}}$ & $8.1 \pm 0.5^{\mathrm{b}}$ & $3.6^{\mathrm{a}} \pm 0.5^{\mathrm{a}}$ & $6.8 \pm 0.6^{\mathrm{b}}$ \\
\hline
\end{tabular}

Different superscripts between the groups denote significant differences $(\mathrm{P}<0.01$ for a and $\mathrm{b}$, and $\mathrm{P}<0.05$ for a and $\mathrm{c})$. * The LH concentration was measured for two experimental and two control bulls, and the testosterone and estradiol-17 $\beta$ concentrations were measured in five experimental and four control bulls.

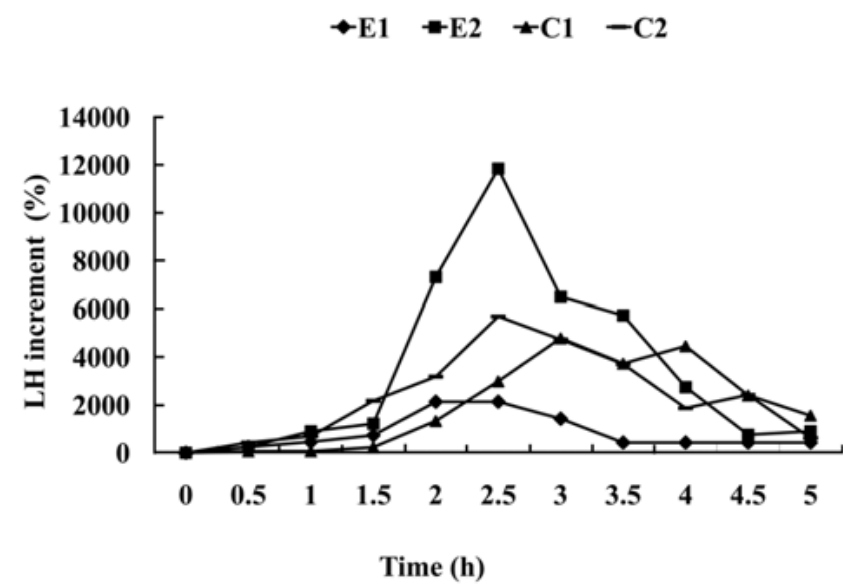

Fig. 1. LH increment until $5 \mathrm{~h}$ post-GnRH treatment in 2 experimental (E1 and E2) and 2 control (C1 and C2) bulls.

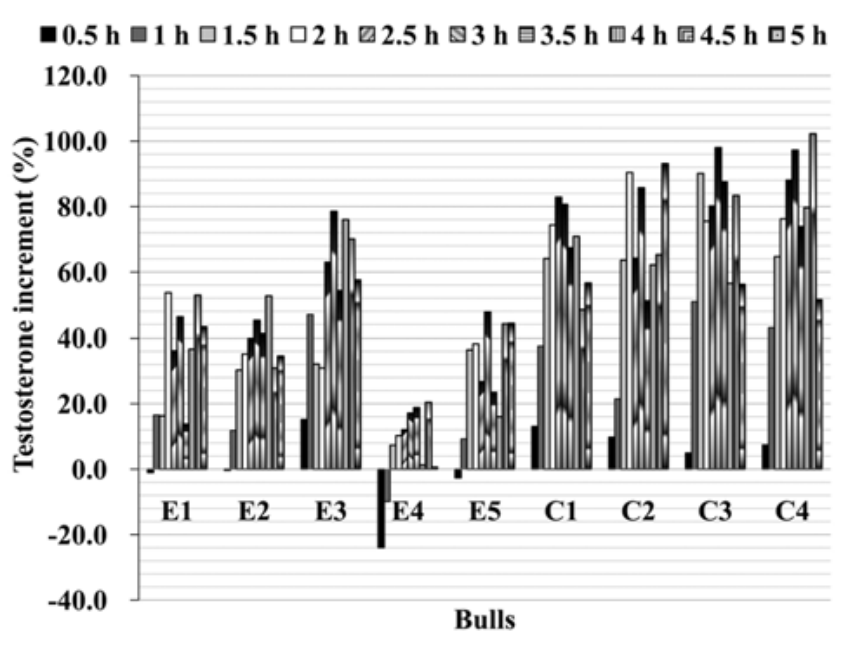

Fig. 2. Per bull testosterone increments until $5 \mathrm{~h}$ post-GnRH treatment in the experimental and control bulls. E1, E2, E3, E4 and E5 are the experimental bulls, and C1, C2, C3 and C4 are the control bulls.

between two experimental bulls (E1 and E2) on LH responses until 5 h PGT were observed, and the reason for this was not known. However, these two bulls had a similar response in terms of testosterone increments PGT, and we speculate that there may be some pituitary differences in $\mathrm{LH}$ receptors or other mechanisms related to $\mathrm{LH}$ production between these bulls. In the present study, we observed almost the same patterns of LH response PGT in all bulls, a rapid increase and then peak between 2 to $3 \mathrm{~h}$, as previously reported in cattle [16,17] and buffalo bulls [18].

In the present investigation, we compared between the poor and good semen quality bulls in terms of the basal and GnRH-stimulated levels of testicular steroids, testosterone and estrogen. The present result clearly demonstrated delayed and lower response of testosterone increment until $5 \mathrm{~h}$ PGT in the experimental group compared with the control group. Similarly, the $5 \mathrm{~d}$ PGT concentration of testosterone was also lower in the experimental group, and we predict that this may be due to the relatively lower basal testosterone level in the experimental group or the downregulation of testosterone biosynthesis. We suggest that the testosterone response until 5 h PGT may be related to the semen quality param- the LH concentrations of only four bulls, two from each of experimental and control group. Considerable bull-to-bull variations
In the present study, the semen quality of bulls was analyzed first, the bulls were then grouped as poor semen quality bulls (experimental group) and good semen quality bulls (control group) and treated later with GnRH to study the differences between the groups in terms of hormonal responses. Here, we could measure 


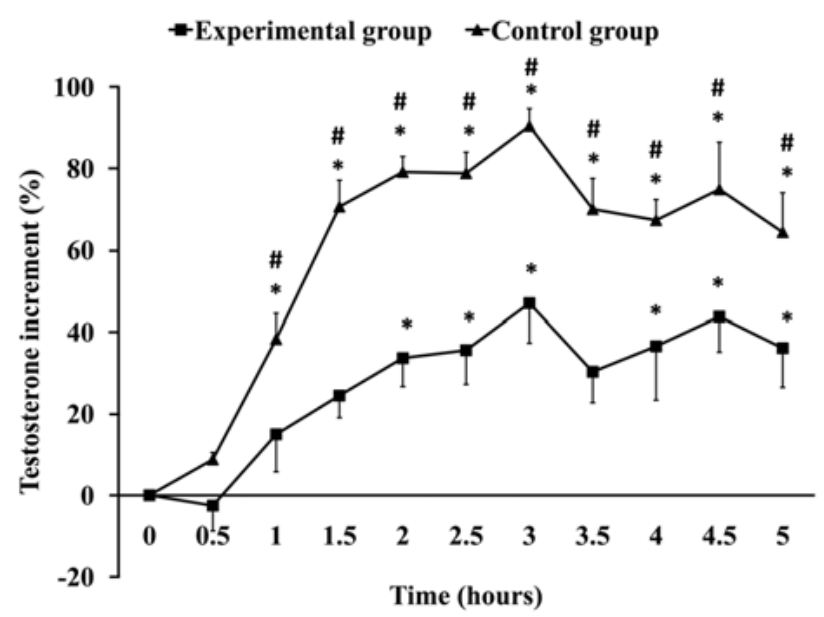

Fig. 3. Average testosterone increment until $5 \mathrm{~h}$ post-GnRH treatment in the experimental and control groups. * Significant increment $(\mathrm{P}<0.05)$ compared with $0 \mathrm{~h}$. \# Significant difference $(\mathrm{P}<0.05)$ between groups for the same time.

eters in bulls, which also supports a previous report that treatment with GnRH and assessment of plasma testosterone concentrations has some correlation with bull fertility and it could be a useful test in bull selection for their reproductive potential [12].

We also studied various morphological abnormalities of the spermatozoa in four out of the five experimental bulls and observed that an average of $>30 \%$ of the spermatozoa in these bulls before and after freezing were morphologically abnormal. Moreover, the percentage of morphological abnormalities after freezing and thawing of spermatozoa in these experimental bulls was much higher than the acceptable percentage abnormality as shown in one control bull as a reference. We believe that similar morphological abnormalities of the spermatozoa could have been observed in the fifth experimental bull as well, which also had poor parameters of spermatozoa concentration, MAC and MAT, that were similar to those of the other four experimental bulls. Furthermore, these observations about the morphological abnormalities of the spermatozoa in the experimental bulls also strongly supported the poor parameters of spermatozoa concentration, MAC and MAT in these bulls. However, the grouping of bulls as having either poor or good semen quality in the present study was primarily based on the spermatozoa motility parameters because we could not study the morphological abnormalities of all the semen samples from every bull. Such semen quality parameters have also been used to identify low fertility bulls [8]. A positive correlation was reported in Ayrshire bulls between GnRH-induced testosterone concentration and fertility of bulls with inferior spermatozoa motility [19]. We also predict that one experimental bull (E3) having a testosterone increment of $>60 \%$ until 5 h PGT may have better fertility than other experimental bulls. Moreover, the present finding of the peak plasma testosterone concentration $3 \mathrm{~h}$ after $\mathrm{GnRH}$ treatment is consistent with the previous reports in bulls [17] and buffalo bulls [18]. Interestingly, four out of the five (80\%) low semen quality bulls here were observed with a testosterone increment of $<60 \%$ PGT.

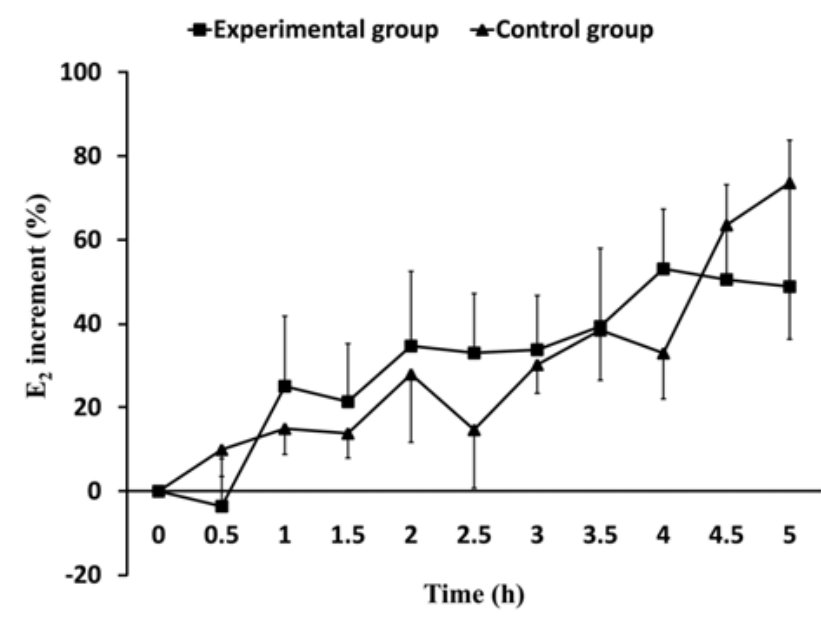

Fig. 4. Average estradiol-17 $\beta$ increment until $5 \mathrm{~h}$ post-GnRH treatment (PGT) in the experimental and control groups.

On the basis of this preliminary result obtained by using only five low semen quality bulls, we suggest that a larger number of bulls should be sampled at $0 \mathrm{~h}$ and $3 \mathrm{~h}$ PGT and that the testosterone increment should be measured to establish if an increment of $<60 \%$ can be a reliable tool to identify bulls having low semen quality.

Our recent study about the testicular pathology in poor semen quality bulls demonstrated mixed atrophic lesions in the testis, in which several seminiferous tubules were Sertoli cell-only tubules without germ cells, and the Sertoli cells showed indications of reversion of maturity [1]. In the same study, we also observed dysplastic lesions in the testes of one bull, characterized by severely shrunken seminiferous tubules with a few intratubular cells and increased interstitial tissue, mostly fibrous in nature. This indicates that the testes of poor semen quality bulls may have various testicular pathologies involving the seminiferous tubules and interstitial cells, which may be related to the morphological abnormalities of spermatozoa and poor parameters of spermatozoa concentration, MAC and MAT as observed here in the experimental bulls. Although not yet understood in the bovine testis, the LH receptors in the rat testis [20] and enzymes responsible for testosterone synthesis in the testes of other ruminants, such as Hokkaido sika deer [21] and Shiba goat [22], are localized in the interstitial Leydig cells. We speculate that there may have been a possible alteration of the LH receptors or the enzymes required for steroidogenesis in the testis of the present experimental bulls that might have led to delayed and lowered GnRH-induced testosterone response.

To the best of our knowledge, this is the first report that has evaluated the basal level and PGT response of $E_{2}$ in bulls. The significantly lower basal, 5 h PGT and 5 d PGT E 2 concentrations in the experimental group were interesting observations of the present study. The peak $\mathrm{E}_{2}$ increment during $5 \mathrm{~h}$ PGT was observed at $4 \mathrm{~h}$ in the experimental group, while the $\mathrm{E}_{2}$ increment increased until $5 \mathrm{~h}$ in the control group. The time interval between the testosterone peak and $\mathrm{E}_{2}$ peak may suggest the time required for 
aromatization of testosterone into $\mathrm{E}_{2}$. The aromatase activity in the mature bull testis is not known, and the alteration, if any, in the pathological testis needs to be investigated. It has been reported that aromatase knockout (ArKO) mice had normal spermatogenesis at the onset of puberty, but that fertility decreased with aging [23]. Similarly, a decrease in sperm motility has been reported in a man with aromatase deficiency [24], and acquisition of sperm motility in humans is related to aromatase activity [25]. These reports indicated that some relationships exist between lower aromatase activity or lower production of estrogen and fertility and spermatozoa motility. Our recent in vivo data has also indicated a positive correlation between estrogen and spermatozoa motility in the postpubertal bulls [14]. Although the morphological abnormalities of the spermatozoa observed here in the experimental bulls might have a direct relation to the decreased spermatozoa motility, we also suggest some indirect relationship between the decreased level of estrogen and the decreased MAC and MAT observed in these bulls.

In conclusion, the peak GnRH-induced testosterone increment in bulls can be assessed at around $3 \mathrm{~h}$ PGT. Poor semen quality bulls may have a delayed and lower GnRH-induced testosterone response. These bulls may also have a lower level of estrogen.

\section{Acknowledgments}

We would like to acknowledge the assistance provided by Dr S Haneda, Dr Y Hirano, Dr A Montoya Carlos and Mr E Kaneko of Obihiro University during animal experiments and hormone measurement, and the staffs of Genetics Hokkaido and the National Livestock Breeding Center, Niikkappu, Hokkaido, for handling the animals while collecting semen and blood samples. The first author was supported by a Monbukagakusho Scholarship from the Ministry of Education, Culture, Sports Science and Technology of Japan, and we are thankful for the scholarship support.

\section{References}

1. Devkota B, Sasaki M, Matsui M, Takahashi K-I, Matsuzaki M, Koseki T, Miyake YI. Effects of scrotal insulation and pathological lesions on alpha-smooth muscle actin (SMA) and vimentin in the bull testes. J Reprod Dev 2010; 56: 187-190.

2. Baron E, Weiss DB, Gottschalksabag S, Zukerman Z. The relationship between plasma levels of gonadotrophins, androgens and prolactin in azoospermic men with their testicular spermatogenic pattern. Fertil Steril 1995; 64: 1043-1045.

3. Billig H, Chun SY, Eisenhauer K, Hsueh AJW. Gonadal cell apoptosis: hormone-regulated cell demise. Hum Reprod Update 1996; 2: 103-117.

4. Martin-du Pan RC, Campana A. Physiopathology of spermatogenic arrest. Fertil Steril 1993; 60: 937-946.

5. Noguchi J, Yoshida M, Ikadai H, Imamichi T, Watanabe G, Taya K. Age-related changes in blood concentrations of FSH, LH and testosterone and testicular morphol- ogy in a new rat sterile mutant with hereditary aspermia. J Reprod Fertil 1993; 97: 433439

6. Bolt DJ, Rollins R. Development and application of a radioimmunoassay for bovine follicle stimulating hormone. J Anim Sci 1983; 56: 146-154.

7. Moura AA, Erickson BH. Testicular development, histology, and hormone profiles in three yearling Angus bulls with spermatogenic arrest. Theriogenology 2001; 55: 1469 1488

8. Watson PF. Artificial insemination and the preservation of semen. In: Lamming GE (ed.), Marshall's Physiology of Reproduction, Churchill Livingstone, Edinburgh; 1990 747-869.

9. Abdel-Malak G, Thibier M. Plasma LH and testosterone responses to synthetic gonadotrophin-releasing hormone $(\mathrm{GnRH})$ or dexamethasone-GnRH combined treatmen and their relationship to semen output in bulls. J Reprod Fertil 1982; 64: 107-113.

10. Gabor G, Mezes M, Tozser J, Bozo S, Szucs E, Barany I. Relationship among testosterone response to GnRH administration, testes size and sperm parameters in Holstein-Frisian bulls. Theriogenology 1995; 43: 1317-1324.

11. Byerley DJ, Bertrand JK, Berardinelli JG, Kiser TE. Testosterone and luteinizing hormone response to $\mathrm{GnRH}$ in yearling bulls of different libido. Theriogenology 1990; 34 1041-1049.

12. Post TB, Christensen HR, Seifert GW. Reproductive performance and productive traits of beef bulls selected for different levels of testosterone response to GnRH. The riogenology 1987; 27: 317-328.

13. Carreau S, Hess RA. Oestrogens and spermatogenesis. Phil Trans R Soc B 2010; 365 1517-1535.

14. Devkota B, Koseki T, Matsui M, Sasaki M, Kaneko E, Miyamoto A, Amaya Montoya C, Miyake Y-I. Relationships among age, body weight, scrotal circumference, semen quality and peripheral testosterone and estradiol concentrations in pubertal and postpubertal Holstein bulls. J Vet Med Sci 2008; 70: 119-121.

15. Kanematsu S, Sato N, Hashizume T. Effects of cholecystokinin on luteinizing hormone release from perifused hypothalamus-pituitary in the castrated bulls. Jpn J Anim Reprod 1990; 30: 54-59.

16. Gabor G, Sasser RG, Kastelic JP, Coulter GH, Everson DO, Falkay G, Mezes M, Bozo S, Cook RB, Csik V, Barany I, Szasz F Jr. Endocrine and thermal responses to GnRH treatment and prediction of sperm output and viability in Holstein Frisian Bulls. Theriogenology 1998; 50: 177-183.

17. Post TB, Reich MM, Bindon BM. Characterization of LH and testosterone response to intramuscular injection of GnRH in tropical postpubertal bulls. Theriogenology 1987; 27: 305-315.

18. Abdel-Malak G, Essawi SA, Youssef RH, Soliman FA. Testicular response to GnRH in buffalo bull. Anim Reprod Sci 1992; 27: 123-128.

19. Anderson M. Relationships between GnRH-induced testosterone maxima, sperm motility and fertility in Ayrsgire bulls. Anim Reprod Sci 1992; 27: 107-111.

20. Huhtaniemi I, Bergh A, Nikula H, Damber J-E. Diffenences in the regulation of steroidogenesis and tropic hormone receptors between scrotal and abdominal testes of unilaterally cryptorchid adult rats. Endocrinol 1984; 115: 550-555.

21. Hayakawa D, Sasaki M, Akabane C, Kitamura N, Tsubota T, Suzuki M, Yamada J Immunohistochemical localization of steroidogenic enzymes in the testis of Hokkaido Sika deer. J Vet Med Sci 2004; 66: 1463-1466.

22. Weng $Q$, Medan MS, Ren L, Watanabe G, Tsubota T, Taya K. Immunolocalization of steroidogenic enzymes in the fetal, neonatal and adult testis of the Shiba goat. Exp Anim 2005; 54: 451-454

23. Robertson KM, Simpson ER, Lacham-Kaplan O, Jones ME. Characterization of the fertility of male aromatase knockout mouse. J Androl 2001; 22: 825-830.

24. Carani C, Qin K, Simoni M, Faustini-Fustini M, Serpente S, Boyd J, Korach KS, Simpson ER. Effect of testosterone and estradiol in a man with aromatase deficiency. N Engl J Med 1997; 337: 91-95.

25. Lambard S, Galeraud-Denis I, Bouriama H, Bourguiba S, Chocat A, Carreau S Expression of aromatase in human ejaculated spermatozoa: a putative marker of motility. Mol Hum Reprod 2003; 9: 117-124. 